\title{
A CONTRAMÃO DOS PROGRAMAS DE EDUCAÇÃO EM SAÚDE: ESTRATÉGIAS DE DIABÉTICOS ${ }^{1}$
}

\author{
THE PROBLEMS OF EDUCATIONAL PROGRAMS IN HEALTH: STRATEGIES OF \\ DIABETICS
}

\section{A CONTRAPELO DE LOS PROGRAMAS DE EDUCACIÓN EN SALUD: ESTRATEGIAS DE DIABÉTICOS}

Cláudia Maria de Mattos Penna² Lícia Maria Oliveira Pinho ${ }^{3}$

\begin{abstract}
RESUMO: Este artigo tem como objetivo refletir sobre o processo de educação em saúde vivenciado pelo sujeito diabético ao enfrentar as proibições e limitações impostas pela doença e pelos profissionais da saúde. Fundamentou-se na Sociologia Compreensiva de Michell Maffesoli, que ao estudar o quotidiano revela que o ser humano faz uso das transgressões e do jogo duplo para driblar as normas impostas pelo viver em sociedade. Calar-se, guardar segredo, não dialogar, parecem ser estratégias que refletem nosso educar em saúde.

PALAVRAS-CHAVE: diabetes, educação em saúde, enfermagem
\end{abstract}

ABSTRACT: The present paper had as objective to reflect on the health education process faced by the diabetic person when confronted with prohibitions and limitations imposed by the disease and health professionals. As framework, the paper relied on Michell Maffesoli 's Comprehensive Sociology which, through the study of daily life, reveals that the human being uses transgressions and double games to escape the rules imposed by society. To silence, to keep secret, not to dialogue, seems to be strategies that reflect our way of doing health education. KEYWORDS: health education, diabetes mellitus, nursing

RESUMEN: El artículo tiene por objeto reflexionar sobre el proceso de educación en salud vivido por el sujeto diabético al enfrentarse con las prohibiciones y limitaciones impuestas por la enfermedad y por los profesionales de la salud. El estudio está fundamentado en la Sociología Comprensiva de Michell Maffesoli, quien al estudiar lo cotidiano, ha revelado que el ser humano hace uso de las transgresiones y el doble juego para escamotear las normas impuestas por la vida en sociedad. Callarse, guardar secreto, no dialogar, parecen ser estrategias que reflejan nuestra forma de educar en salud.

PALABRAS CLAVE: diabetes, educación en salud, enfermería

Recebido em 18/10/2001

Aprovado em 06/02/2002

\footnotetext{
'Elaborado a partir da dissertação de mestrado "Educação em Saúde no quotidiano do ser diabético." Escola de Enfermagem da UFMG-Minas Gerais, 2000.

${ }^{2}$ Professora. Doutora em Filosofia de Enfermagem. Faculdade de Enfermagem Concórdia-SC

${ }^{3}$ Professora. Mestre em Enfermagem. Faculdade de Enfermagem - Universidade Católica de Goiás.
} 


\section{INTRODUÇÃO}

Como professora do Curso de Enfermagem da Universidade Católica de Goiás desenvolvi, junto com acadêmicos do nono período, ações de enfermagem, entre elas educação em saúde no programa de doenças crônico degenerativas Diabetes, na unidade básica de saúde (UBS) - Flamboyant ${ }^{4}$, programa de referência para a região noroeste da cidade de Goiânia.

A assistência ao cliente portador de diabetes fez-me refletir e estudar sobre o educar em saúde, seus objetivos, expectativas e áreas de atuação do referido programa. Com o passar dos anos, fui me aproximando cada vez mais dessa clientela. Pude então perceber a dificuldade deles em aceitar uma doença crônica, bem como todas as limitações impostas por ela, o que suscitou alguns questionamentos sobre o processo educativo realizado no programa; dessa forma, na tentativa de encontrar respostas para minhas inquietações, comecei a observar as ações educativas desenvolvidas no referido programa e sua receptividade pelo cliente.

O convivio freqüente trouxe a certeza do quanto era marcante a dificuldade daquelas pessoas em aceitar a própria doença. Foi um periodo enriquecedor para mim, pois, como cidadã e educadora, pude compartilhar experiências com o grupo em questão. A cada reunião que participava, ficava mais sensibilizada com os discursos dos clientes, cujo sofrimento e a perda eram sentimentos sempre presentes.

Ao ingressar no curso de mestrado, propus como trabalho de conclusão compreender o ser diabético e o processo educativo para o sujeito que o vivencia.

De maneira geral educar depende da visão de mundo de quem educa, o que na maioria das vezes determina o rumo das percepções dos educandos e talvez por isso mesmo o jogo duplo faz-se presente. Entretanto, educar

capacidade para um interagir consigo mesmo e com o mundo.

Consoante a esse pensar, Zampieri (1999, p. 207) diz que "o educar-se dá-se a partir da interação, seja consigo, com os outros ou com o meio ambiente".

Pensando para além disto; busquei uma reflexão que revelasse o lado criativo do educar. Encontrei, em Freire (1999) que ensinar não é transferir conhecimentos; é sim criar possibilidades para sua construção e produção.

Nesse sentido, Bezerra (1998, p. 252) relata: "a educação permeia a sociedade". Assim, para que ela exista, é necessário socializar o sujeito, ou seja, fazê-lo capaz de interpretar a realidade que o cerca, realizar e experimentar opções e transformá-las em decisões. Construção, produção e transformação são resultados do educar que visam promover crescimento.

Assim também pensa Villa (2000) quando coloca que o educar deve promover o crescimento da pessoa, dando-lhe oportunidade de ser ela mesma. Para tanto, faz-se indispensável que os educadores em saúde conheçam a realidade, a visão de mundo e as expectativas de cada sujeito, para que possam priorizar as necessidades dos clientes e não as exigências terapêuticas.

É nesta perspectiva que hoje percebo a educação: aprendendo a notar a presença do outro e respeitando seu saber, na busca de uma complementação.

\section{CAMINHO METODOLÓGICO}

Este estudo foi realizado com a clientela participante de um programa de educação em saúde para Diabetes da UBS- Flamboyant no município de Goiânia- GO. Os sujeitos da pesquisa foram dez pessoas diabéticas que se dispuseram a descrever para mim como vivenciavam o processo educativo do qual participavam, para que eu pudesse compreendêlo. Todos os entrevistados freqüentam o programa há mais de um ano.

Reconhecendo, como Bakhtin, citado por Minayo (1996, p. 110), que "a palavra é o modo mais puro e sensivel de relação social... o material privilegiado de comunicação na vida cotidiana é a palavra," a principal fonte de informações foram os clientes diabéticos através da entrevista. As entrevistas foram gravadas e transcritas imediatamente, para que não se perdessem informações importantes à compreensão do fenômeno estudado.

Formulei duas questões norteadoras: 1) Fale para mim o que é ser diabético. 2) Qual a sua percepção em relação às ações de educação em saúde, realizada pela enfermeira, no atendimento do programa?

Para enriquecer as falas dos entrevistados e na tentativa de buscar mais informações referentes ao fenômeno, utilizei a observação. Quando falamos em observação, concordamos com Trentini e Paim (1999, p. 88) ao afirmarem que ela deve ser “...consciente, objetiva, formalizada e exteriorizada de maneira que seja exposta à compreensão de outras pessoas."

Após as transcrições e leitura das entrevistas, percebi convergências, repetições e invariantes nos

${ }^{4}$ Nome fictício da unidade básica de saúde em questão. 
discursos, chegando então à saturação das informações, o que me fez encerrar a coleta de informações após dez entrevistas.

Este estudo tem caracteristica qualitativa, fundamentado na Sociologia Compreensiva de Michel Maffesoli. A Sociologia Compreensiva entende que o mundo está em constante movimento, por isso acredita que a construção da realidade parte do sujeito, de sua vivência, subjetividade e experiências. Penna (1997) lembra que tal ramo da sociologia está baseada na busca da compreensão da experiência vivida por cada indivíduo, em um determinado espaço de tempo.

\section{ANÁLISE DAS INFORMAÇÕES}

Ao dizer ela dá o total, ela manda, eles querem, eles pedem, como aparece nos relatos dos sujeitos, eles denunciam a unilateralidade e o autoritarismo dos profissionais de saúde quando fazem orientações aos clientes do programa. Como podemos ler a seguir:

Uai, bom. Alguma a gente as veis segue, conforme elas pede lá. (...) Então, o jeito dela pra gente comer, é só uma verdura, uma coisa. Mas a gente as veis não tem aquela verdura, o dinheiro, a gente é pobre. O dinheiro pra passar só a verdura, é difícil. É difícil. Quando a gente tem, a gente evita de comer. (...) Então, quando a gente não tem a verdura, o que que a gente tá prá fazer. O jeito é comer aquilo que a gente vê que prejudica a gente...(Azaléia)

Uai, depois que saio de lá, eu faço sempre como eu tô te falano, meu bastão é aquilo mesmo. Não muda e nem diminoi nada. (...) Obedeço direitinho, (...) Cumpro. Eu acho que é por isso que eu ainda sou viva. Porque eu ando certim. Obedeço todas elas (...) Não, se você chegar aqui e falar, olha D.Beta a senhora não pode comer feijão ou arroz, eu não como, entendeu? (Sorriso)

Ela fala. Ela dá o total pra gente fazer o que ela manda. Às veis a gente faz, eu não vou mentir, às vezes eu não faço. As veis eu falo: D. Fulana mandou fazer assim, assim, mas eu não tô fazeno (...) Porque a gente pode comer as veis uma fruta, ela fala: o senhor pode chupar uma laranja cedo, outra à tarde e tem dia que eu chupo logo 5 laranjas num dia. Banana, como é que fala? Tem que ser cada dia uma fruta, mas eu misturo. Tem dia que como 4 ou 5 bananas, 4 ou 5 laranjas, tô fora, não tô fazendo nada sobre o que ela fala (...) Ué, minha vida continua a mesma coisa que eu escutei aquele que tá conversando. $O$ pobrema foi resolver, entender o que a pessoa falou. Cumprir aquilo. Só isso. (Ipê Roxo)

Mas, eu sigo sim, muitas coisas assim eu sigo direitim. Porque eu acho que é muito importante a gente assistir a palestra e seguir também. Porque se não, não tem sentido (...) Mas o mais difícil que eu acho assim é ficar sem comer o doce, o açúcar (...) Muitas vezes a gente nunca que segue o regime certim. Lá algum dia cê sai um pouquinho. Então, não vou te dizer que eu sigo na risca, tudo o que fala não. Porque muitas vezes a gente sai mesmo. E mas eu faço tudo pra vê se controla. (Murici)

Ah! Um pouco sim, outro não. Porque as vezes falta as coisas que eles pedem pra gente fazer, fica faltando. A gente não consegue concluir as coisas que eles querem. Ai fica desse jeito, a gente fica no meio do caminho. Um pouco dá certo, um pouco dá errado (...) as veis fica faltando remédio lá. A gente chega em casa, também não tem dinheiro pra comprar, fica faltando. (Ipê-Amarelo)

Ah! Quando desconfio que tá meio alterado que eu faço exame, dai eu diminuo o jeito de alimentação, de tudo. (...) Ás vezes, lá uma hora, a gente dá uma folguinha e faz um trem que não pode e parece uma coisa que a gente tá com muita vontade de comer, a gente não deixa de não dar uma escorregada... (Umburuçu)

Não é muito fácil. Pra gente fazer do jeitinho que a gente aprende lá. A gente sente um pouco de dificuldade. Muita coisa na alimentação a gente tem dificuldade. As veis não pode comprar, tudo direitinho, como manda lá. A gente tem um pouco de dificuldade (...) Por causa da situação financeira. Porque assim, eles falam assim pra substituir o pão por outra coisa, que eu tenho a lista aí. As vezes eu não posso, o pão é mais barato. Eu não posso substituir por outra coisa. Fruta também as vezes tem dia que a gente não tem o dinheiro pra comprar, aquelas coisas que eles manda a gente substituir duma coisa pra outra (...) Eu vejo muitos clamar que não tem condições de fazer aquela dieta do jeito que manda. Porque não tem condição de comprar aquilo que eles pede. Que eles fala pra gente alimentar. O remédio também, falta demais. (Marcelinha)

Eu não faço muito regime também não. Eu faço regime até um certo tempo, depois parece que melhorou, eu começo a facilitar de novo. (...) Acho que é muito interessante. As orientações lá. Inclusive, eu procuro a seguir bastante. Na medida que a gente pode, a gente segue (...) É..... certinho, não segue. Mas ao menos um bucado a gente segue. (Lírio Amarelo)

Nos fragmentos dos discursos dos sujeitos, percebi a soberania de muitos profissionais de saúde sobre os clientes ao pensarem que detêm o "saber" e o "poder". Eles estabelecem o tratamento e passam para o cliente exatamente o que e como "deve" ser feito, revelando uma metodologia pedagógica autoritária, em que o educar em saúde está acontecendo simplesmente como um transmitir 
conhecimentos de forma unilateral, sem que haja a participação do educando.

A linguagem utilizada por esses profissionais educadores, segundo Olivieri (1985, p. 25), favoreceu a distância entre o educador e o educando pois, "limita o sentido do viver do paciente a uma doença específica num organismo, ... o ser doente está esquecido."

Numa situação como essa, lamentavelmente a pessoa humana está esquecida. Volta-se para a visão cartesiana de se ver o mundo, na qual o profissional está tratando "a doença" e não o ser doente. Ressalta-se sua capacidade técnica, o repasse de conhecimentos, limitados à doença apresentada pelo cliente, esquecendo-se do mesmo e do meio em que esse está inserido. Mas, indo além disso, percebemos também que as escolas de formação dos profissionais de saúde, em geral, ainda preparam o estudante para cuidar das formas agudas da doença, numa tendência de estudar o homem isolado do seu meio ambiente, numa perpetuação da visão cartesiana de mundo.

Um processo como esse ignora a visão de mundo do sujeito que, sem participar de seu próprio tratamento, limita-se ao autoritarismo do profissional (ela dá o total, ela manda, eles querem), num educar que não estimula o desenvolvimento de habilidades intelectuais, não divide responsabilidade e não transforma o cliente em sujeito de seu tratamento. Portanto, é provável que não atinja um dos principais objetivos do programa, que é o de instruir o paciente para que ele possa adequar o esquema terapêutico às suas necessidades diárias e chegar ao autocuidado. O profissional parece esquecer que se torna fundamental dialogar com o cliente, para que ele possa entender o porquê das proibições e limitações que tanto o incomodam.

Percebe-se, daí, a falta da participação ativa do cliente na elaboração do seu plano terapêutico, o que provavelmente o deixa dependente do profissional. Sem ser ouvido, sem ter seu saber acreditado e valorizado, e sem se sentir integrado ao seu tratamento, resta-lhe ouvir e guardar o que é conveniente, para em seguida fazer como pode no seu quotidiano, aceitando e calando-se em função dos benefícios que tem em troca, como, por exemplo; a facilidade em marcar consultas, exames, obter medicamentos, adoçantes e outros.

Como diz Nascimento (1995, p. 42), "na resistência às diversas formas de poder, não há uma recusa acintosa ou uma adesão explícita aos valores propostos ou às normas impostas." O cliente usa de astúcia para recusar e continuar participando do programa e faz do silêncio um intermediário de suas relações com o profissional. Nesse jogo, perdem o profissional e o cliente por não manterem um diálogo aberto, preferindo o não dizer, prejudicando-se numa relação não transparente e ambígua.

Sabemos que o escutar é fundamental na comunicação. Quando não paramos para escutar, não percebemos que, para o cliente, o grande problema foi resolver entender o que a pessoa falou. Ao não se parar para perguntar se houve entendimento das orientações, acaba-se por desrespeitar o cliente, apesar de se afirmar que o mesmo é um cidadão com direitos e deveres. Quando utilizamos de linguagem muito técnica, deixamos o cliente a imaginar o que pode ser aquilo, o que foi que ela falou para nós. Deste modo indagamos: onde fica a troca de saberes? Como lidar com as dificuldades e a angústia do dever não cumprido, se não há espaço para o diálogo?

Relembrando a rotina de uma consulta de enfermagem, não poderia deixar de relatar o autoritarismo de um enfermeiro, que, nesta hora, parece acreditar que está num patamar tão acima do cliente a ponto de lhe dizer o que é melhor e o que ele deve fazer. Ao final parece não perceber que o cliente nada falou, nada contestou e ainda saiu sorrindo, se com as mesmas angustias ou não, não the interessa, pois está convencido que fez muito bem sua parte e ainda afirma: dei uma bela aula sobre diabetes.

Entretanto, as dúvidas permanecem, então, quando a gente não tem a verdura, o que devemos fazer? ; sem condições para driblar a situação, fica no meio do caminho e não consegue concluir o que eles mandam, ficando tudo como está. Continuam a vida como se não tivessem recebido as orientações. Sobre isto diz Rezende (s/d): "Muitas vezes o nosso cliente escuta a orientação, não contesta, mas também não a obedece. Retorna ao posto de saúde em condições piores e pode até mentir para o profissional que, perplexo, não sabe o que dizer."

Calar-se e guardar segredo podem ser as soluções encontradas pelo sujeito para continuar freqüentando o programa, beneficiando-se do que for possivel e mantendo um bom relacionamento com o profissional de saúde. Para tanto, utiliza-se do jogo duplo como uma forma de proteger-se das ordens dificeis de serem cumpridas. Assim, o sujeito esquivase para que não ocorra afrontamento de valores entre ele e o profissional. Segundo Maffesoli (1984, p. 118), o jogo duplo é uma maneira de responder ao artificialismo de uma sociedade; diz ele: "A duplicidade será uma maneira de nos protegermos contra todas as formas de absolutização, traduzindo, portanto, a contingência humana." Desse modo não se segue à risca tudo que falam, porque não é muito fácil fazer do jeitinho que é ensinado; a gente sente um pouco de dificuldade. Assim, não se consegue obedecer e continua-se fazendo da melhor maneira possivel.

Toda sociedade parece viver de encenação. Vivemos um grande teatro, onde as representações, 
o jogo duplo, as máscaras e a transgressão são reciprocas e fazem parte das relações interpessoais, o que não significa agressão à moral, mas algo essencial ao convivio social. Como diz Petitat (1998), a sociedade dá a cada indivíduo o direito de não dizer, fazendo respeitar sua zona de intimidade ou zona de autonomia interior. Utilizando-se de seus direitos, os sujeitos desse estudo muitas vezes não revelam ao profissional suas reais dificuldades.

A decisão de manter segredo mostra a passividade, o viver solitário e o virar-se sozinho do sujeito diabético, que usa de astúcia para enfrentar as imposições do viver em sociedade. Nessa perspectiva, Maffesoli (1984:124) declara que,

\footnotetext{
... a máscara, o jogo duplo oferecem um refúgio bastante seguro, permitindo existir, ser - no sentido mais forte do termo - fazendo como todo o mundo. A máscara, a polidez, os costumes, o conformismo etc. são como uma modulação quase intencionais da astúcia organicamente ligada à vida, astúcia que, de alguma maneira, justifica a própria existência.
}

O querer viver em liberdade exige, então, do sujeito o uso de máscara e do jogo duplo para esquivarse das imposições da vida, do autoritarismo do profissional de saúde, frente ao seu tratamento. $\mathrm{O}$ sujeito transgride calando-se e arriscando-se e lá uma hora a gente dá uma folguinha, muitas vezes a gente nunca que segue o regime certinho; arrisca-se, assim, a ter uma hiperglicemia pelo prazer de sentir 0 verdadeiro gosto de viver.

Segundo Le Breton (1995, p. 10), "o arriscarse possui uma conotação positiva, muitas expressões afirmam: 'a sorte sorri aos audaciosos', ou 'quem não arrisca, nada tem.' Assim, o sujeito diabético está sempre se arriscando. Vive em constante perigo, sendo que este é inerente à vida, pois de nada valeria viver se optássemos por uma vida de extrema rotina, sem correr qualquer tipo de risco, se é que existe esta possibilidade.

Concordamos com o autor acima citado quando afirma que: Conhecer o risco é a melhor prevenção contra ele. Assim faz o sujeito ao interagir com a doença, conhecendo-a e familiarizando-se com os sinais e sintomas. Quando desconfio que tá meio alterado, eu diminuo o jeito da alimentação, demonstrando conhecer as respostas de seu organismo, quando submetido a algum risco. Dessa forma, o sujeito arrisca-se consciente para viver uma vida com gosto de aventura, temperando sua triste vida de ser diabético, driblando a morte e vivendo seu tempo cíclico pelo caminho mais longo que puder percorrer. Arriscando-se, transgredindo, vive-se este tempo cíclico que se contrapõe ao tempo linear, estabelecido cronologicamente, marcado pelo nascimento, crescimento, velhice e morte, ou seja, o tempo cíclico renova-se a cada dia afastando a angústia estabelecida pela finitude do tempo linear, como nos fala Maffesoli (1984, p. 84), " ... a repetição é certamente um meio que uma estruturação social dada possui de negociar com a morte, de gerir sua angústia frente à aceleração da história."

Cada sociedade possui formas diferentes de representar o viver. Cada grupo tem sua existência marcada por costumes e prazeres diferentes. Para o sujeito diabético, o prazer de comer é elucidado a cada momento por ser limitado pela doença. Não poder comer carboidratos e doces, por exemplo, provoca angústia e desânimo. O arriscar-se e de vez em quando comer o que é proibido, apesar da contradição que se estabelece, parecem ser uma forma de ter a sensação de viver melhor, renovando o contrato com a vida e adiando a morte.

Os profissionais de saúde precisam entender que o sujeito diabético é um ser que vive, que se arrisca como todo ser vivo e que, portanto, deve ser tratado como tal. Atualmente, o poder constituído pelo profissional, em nome da promoção da saúde, geralmente limita-se a proibições, as quais restringem as ações do cliente e levam, obviamente, à violação. Assim, o próprio profissional induz à transgressão, sem perceber. Transgredir é uma forma de dizer não às ordens e normas. Transgredir e não revelar é tentar escapar ao constrangimento de ser doente, imposto pela sociedade. Isto acontece com o sujeito diabético quando passivamente aceita as orientações prescritas pelo profissional de saúde e impostas pela doença, mas não as obedece, arriscando-se, dando-se o direito de viver com mais prazer, como diz Maffesoli (1984, p. 119), "...a partir da limitação e da imposição criase uma arte de viver que tem como centro a distância que permite o jogo duplo... a eterna atitude de resistência frente aos pesos mortiferos que todas as estruturações sociais segregam naturalmente."

A arte de viver criada pelo sujeito diabético, com a finalidade de manter o bom relacionamento que estabeleceu com os profissionais de saúde do programa, remete ao prazer de estar-junto, em que a afetividade e o amor tornam possivel minimizar sentimentos como o medo e a tristeza, existentes em seu quotidiano, conforme o autor supracitado (1996, p. 84) afirma, “... primordial no caso é o sentimento de vida, a sensação do viver (...) olhar sobre os sentidos constitutivos da vida humana, e a lembrar que, na sua simplicidade, esses são incontornáveis, e que determinam a matriz de toda existência social."

Apesar dos sentimentos expostos e das dificuldades encontradas no quotidiano de uma pessoa com Diabetes Mellitus, a vontade de viver está demonstrada no arriscar e na opção de fazer um jogo duplo para driblar a morte, conquistar a vida, interagir bem com o profissional de saúde e com sua 
metodologia de educação. Marca-se assim, o existir de um grupo que vive em sociedade, na esperança de um dia curar-se e, quem sabe, livrar-se de uma vez por todas do Diabetes.

\section{CONSIDERAÇÕES FINAIS}

É necessário, portanto, que enquanto profissionais de saúde, em nosso papel de educadores, repensemos as formas de conduzir o processo educativo. Não existem fórmulas mágicas para tal, mas o compartilhamento de saberes é possivel em qualquer lugar. Antes de qualquer orientação, informação, prescrição, devemos reconhecer que cada cliente é um ser humano, que constrói uma história, tem conhecimento de si, saberes que lhes são próprios e que naquele momento está acometido de uma doença. É a proposta de transgredir a visão cartesiana de mundo e ao buscar estar junto do cliente, resgatar o sentido de um verdadeiro processo ensino aprendizado tão falado na educação em saúde, no qual todos ensinam e aprendem.

\section{REFERÊNCIAS BIBLIOGRÁFICAS}

BEZERRA, A.L.Q. A educação permanente: a manutenção da qualidade. In: CONGRESSO BRASILEIRO DE ENFERMAGEM, 50., 1998, Salvador. Anais... Salvador: Associação Brasileira de Enfermagem, 1998. p.250-257.

FREIRE, P. Pedagogia da autonomia: saberes necessários à prática educativa. 12. ed. Rio de Janeiro: Paz e Terra, 1999. 165p.

LE BRETON, D. La sociologie du risque. Tradução livre de Laysa de Faria Soares. Paris: PUF, 1995. 127p.
MAFFESOLI, M. A conquista do presente. Rio de Janeiro: Rocco, 1984. 167p.

MINAYO, M.C.S. O desafio do conhecimento: pesquisa qualitativa em saúde. São Paulo: Hucitec, 1996. 269p.

NASCIMENTO, E. S. Noções que animam o quotidiano. Rev. Enfermagem PUC MG, Belo Horizonte, v.2, n.4, p.3945, dez. 1995.

OLIVIERI, D. P. O "ser doente": dimensão humana na formação do profissional de saúde. São Paulo: Moraes, 1985. 81p.

PENNA, C.M.M. Ser saudável no quotidiano da favela. Pelotas: Editora Universitária/UFPEL, 1997. 155p.

PETITAT, A. Segredos e formas sociais. Tradução para fins didáticos de Maria Imaculada de Fátima Freitas. Paris: PUF, 1998. Cap.4, p.81-113: Segredo e morfogênese social.

REZENDE, A.L.M. Quotidiano, saúde e doença: um olhar compreensivo. [s.n.t.]. Digitado.

TRENTINI, M.; PAIM, L. Pesquisa em enfermagem: uma modalidade convergente-assistencial. Florianópolis: UFSC, 1999.162p.

VILLA, E.A. O enfermeiro-educador no mundo da enfermagem. Belo Horizonte, 2000. 104 f. Dissertação (Mestrado em Enfermagem) - Escola de Enfermagem da UFMG.

ZAMPIERI, M.F.M. Vivendo o processo educativo em enfermagem com gestantes de alto risco e seus acompanhantes. Texto e Contexto Enfermagem, Florianópolis, v.8, n.1, p. 203-221, jan./abril. 1999. 